\title{
Drain Rate and Liquid Level Simulation in Blast Furnace Hearth Using Plant Data
}

\author{
Hemant Upadhyay ${ }^{1}$ and T. K. Kundu ${ }^{2}$ \\ ${ }^{1}$ Blast Furnace Department, Jindal Steel \& Power Ltd., Raigarh, Chhattisgarh 496001, India \\ ${ }^{2}$ Department of Metallurgical and Materials Engineering, Indian Institute of Technology Kharagpur, Kharagpur, \\ West Bengal 721302, India
}

Correspondence should be addressed to T. K. Kundu; tkkundu@metal.iitkgp.ernet.in

Received 29 May 2013; Accepted 2 July 2013

Academic Editors: M. Carboneras, P. Markovsky, and A. Pinkerton

Copyright (C) 2013 H. Upadhyay and T. K. Kundu. This is an open access article distributed under the Creative Commons Attribution License, which permits unrestricted use, distribution, and reproduction in any medium, provided the original work is properly cited.

\begin{abstract}
Proper understanding and control of drainage of hot metal and slag from hearth are essential for a stable and efficient blast furnace operation. Various operational problems like irregular casting intervals, damage to lining, low blast intake, furnace pressurization, and so forth are normally encountered when liquid levels in the hearth exceed a critical limit where hearth coke and deadman start to float. Estimation of drain rate and liquid level in hearth needs to be simulated based on the operating parameters available as carrying out any direct measurement is extremely difficult due to the hostile conditions. Here, a mathematical model has been developed to simulate real-time liquid level and drainage behavior of the furnace hearth. Based on the computed drainage rate, production rate, and mass balance, the model is able to predict occurrence of slag-out time and cast close time which are in good agreement with the plant data.
\end{abstract}

\section{Introduction}

The iron-making blast furnace $(\mathrm{BF})$ is a giant countercurrent heat exchanger and chemical reactor used for reduction of iron ore to molten iron. It is the most important commercial reactor for producing the majority of the world's primary steel. To improve blast furnace productivity, iron and steel industries are constructing larger furnace having more than $4000 \mathrm{~m}^{3}$ internal capacity. Effective drainage of molten iron and slag from the hearth is the major problem occurring in larger-capacity and higher-productivity blast furnaces.

Proper drainage of blast furnace (BF) hearth is very important in order to maintain smooth hot metal production and stable burden descent. The condition of the hearth plays an important role, since it affects the reduction of the leftover $\mathrm{FeO}$ in slag [1], the dissolution of carbon in liquid iron, the distribution of various solutes between iron and slag, and the fresh hot metal flow from the dripping zone [2]. Inadequate drainage can make the blast furnace operation problematic when liquid levels exceed a critical limit characterized by very short distance between slag surface and raceways. Furthermore, at an elevated liquid level, the buoyancy force acting upon the coke column increases, and the deadman starts to float, causing sluggish or irregular descent of burden material. Therefore, it is very important for furnace operators to understand the mechanisms governing hearth drainage and access internal state of the liquids in the hearth. This knowledge is very important in order to take appropriate control actions to ensure a good drainage of liquids from the hearth and thereby guarantee a stable BF operation with minimum wear of the hearth linings [3]. Unfortunately, it is very difficult to carry out any direct measurement because of the hostile conditions in the blast furnace hearth, with high-temperature and chemically aggressive liquids. Hence, the estimation of drain rate and liquid level in hearth has to be simulated based on indirect measurements and the available operating parameters. Estimation of liquid levels and tap rates based on the assumption of a stationary or a floating deadman has been reported in the literature $[4,5]$. Hearth liquid level estimation was carried out by strong correlation with 
the electromotive force measured between two electrodes mounted at the furnace shell and iron level in hearth [2]. A mathematical model for flow-rate simulation considering momentum conservation for a fluid flow at unsteady state and the effect of coke bed, pressure gradient, and drag interaction has been developed [6]. Measurements on liquid holdup and average residence time by high-temperature trickle-bed setup using a screw feeder and their modeling have been performed by Husslage et al. [7]. A two-dimensional model considering the simultaneous drainage of iron and slag from a packed bed has been developed by Tanzil and Pinczewski [8], but the estimates of slag residual volume showed large errors when applied to actual blast furnace. Half-cylindrical scale physical model and mathematical balance model have been developed by Nouchi et al., to show the effect of particle-free space on hearth drainage efficiency [9].

Although the above models provide reasonable estimates, they have some deficiencies. They either require a huge infrastructure or involve a lot of variables for metal and slag, whose values are not readily available, and they change significantly with process parameters. In order to solve this problem and provide the furnace operator with a tool to examine and control the tapping, a mathematical model is prepared to simulate the casting practice. Here, blast furnace hearth is considered as a pressurized vessel with a liquid supply from top and a drain (taphole) at bottom. The fluid flow from the taphole is considered to be dynamic and depends on production rate, slag rate, furnace pressure, quality of metal/slag/mud gun clay used, and the erosion behavior of the taphole. These parameters were studied over a large number of castings, and their relationship is established in terms of a tunable flow factor. A set of differential equations were used to represent the variation of flow rate using Bernoulli's principle, mass content, and fluid level in hearth. Based on these calculations, the slag-out time $\left(t_{s}\right)$ and the tapping closure time $\left(t_{c}\right)$ were predicted, and a real-time view of liquid levels in blast furnace hearth is provided.

\section{General Description of the Blast Furnace Hearth Model}

In blast furnace, the solid burden consisting of iron ore lumps (and/or pellet/sinter), coke, and flux (limestone and dolomite) is charged and from top using gas-leak-proof bell-less/double-bell charging system. Hot oxygen-enriched humidified-air blast blown through tuyeres (located just above hearth region) combines with carbon (of coke) at raceways and generates $\mathrm{CO}$ and heat. The hot $\mathrm{CO}$ reduces iron oxides (in the upper part of the furnace) as it ascends toward top, and molten iron and slag (molten oxides formed by gangue and flux) accumulate in the hearth in layers due to immiscibility and difference in specific gravity. The magnified view of the blast furnace hearth is shown in Figure 1, which is drained from a taphole.

The blast furnace hearth is never empty; it is always full of coke and contains varied quantities of metal and slag. Even after tapping, there is always some amount of residual slag in the hearth (Figure 1). Permeability and density of the

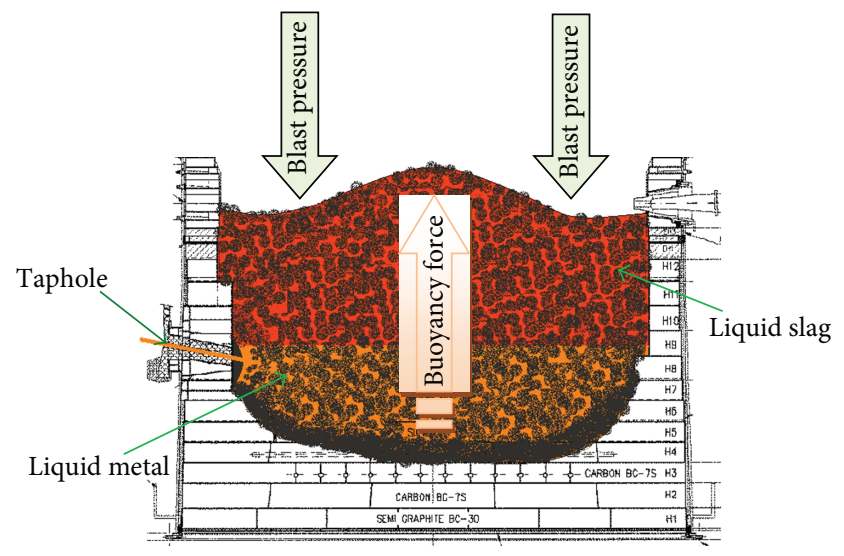

FIGURE 1: Cross-sectional view of blast furnace hearth.

coke grid are not uniform within the hearth; for example, deadman is the least permeable zone in the hearth. The fresh liquids generated are accommodated in the voids between the coke particles; hence, obtaining the representative average void fraction is necessary for hearth modeling. During the tapping, the cross-sectional area of the taphole does not remain constant as it continuously erodes. The rate and type of erosion depend on various factors like quality of clay used to close the taphole, furnace operating parameters, metal/slag quality, and extent of human intervention. As a consequence, the drain rate does not remain uniform. To proceed for any sort of modeling, it is of utmost importance to estimate the taphole erosion coefficient which may be a unique characteristic for each furnace.

The inner height of the BF hearth is generally considered to be from the top of the refractory lining to the tuyere center line, but for drainage calculation, the effective height is considered to be from the taphole center line to the tuyere center line. In order to avoid any mishap due to the rising liquid levels, there must be a defined safety level beyond which the liquid level should not rise. According to the general understanding, the slag being lighter remains on top of the metal layer, and it should come out only after the complete drainage of metal from the hearth. Contrarily, in actual practice, the interface of metal and slag does not remain completely flat, and, on approaching towards taphole, it takes an inclined profile due to which the slag comes out from the hearth before complete drainage of metal. At no point of time, slag comes out through taphole alone and even after drainage of metal layer as the instantaneous quantity of the generated (through dripping zone) metal comes out with the slag. All of these factors were kept in mind, and appropriate values were chosen while calculating the effective average drain rate.

\section{Modeling Methodology}

The delay time $\left(t_{h}\right)$ between closing of last casting and opening of the current casting is obtained in the first step of the drainage calculation. The hot metal and slag production rates $\left(\bar{Q}_{\mathrm{mp}}, \overline{\mathrm{Q}}_{\mathrm{sp}}\right)$ are calculated based on burden, charge 
rate, burden and hot metal compositions and metal losses (assumed to be 1\% here) as received from the process control system of BF-II, JSPL Raigarh Plant. The calculated production rate and the delay time are used to obtain the initial quantities of liquid metal $\left(Q_{m 0}\right)$ and slag $\left(Q_{s 0}\right)$ accumulated in hearth, prior to opening of taphole. The velocities with which the liquid metal $\left(v_{m}\right)$ and slag $\left(v_{s}\right)$ come out through the taphole are calculated using Bernoulli's principle in (1) for flow from pressurized vessel, considering blast pressure $\left(P_{b}\right)$, outer pressure $\left(P_{\text {out }}\right.$, atmospheric pressure), inner pressure $\left(P_{\text {in }}\right.$, pressure at iron-slag interface, i.e., blast pressure plus the slag head pressure), persisting, and instantaneous vertical height of metal and slag levels from taphole $\left(h_{m}, h_{s}\right)$ in hearth. Appropriate values for hot metal and slag densities are taken from the plant operating data $\left(\rho_{m}=6700 \mathrm{~kg} \mathrm{~m}^{-3}\right.$; $\left.\rho_{s}=2800 \mathrm{~kg} \mathrm{~m}^{-3}\right)$. Consider the following:

$$
\begin{gathered}
v_{m}=\sqrt{2 \cdot\left(\frac{P_{\text {in }}-P_{\text {out }}}{\rho_{m}}+g \cdot h_{m}\right)}, \\
v_{s}=\sqrt{2 \cdot\left(\frac{P_{b}-P_{\text {out }}}{\rho_{s}}+g \cdot h_{s}\right)} .
\end{gathered}
$$

Using these velocities along with the cross-sectional area of the taphole $\left(a_{2}\right)$ and with the flow factors $\left(f_{m}, f_{s}\right)$ obtained by calibration with a large number of tapping results (as described later in this section), the drain rates of metal and slag $\left(\bar{Q}_{\mathrm{md}}, \bar{Q}_{\mathrm{sd}}\right)$ at any point of time are derived as follows:

$$
\begin{gathered}
\frac{d Q_{\mathrm{md}}}{d t}=-v_{m} \cdot a_{2} \cdot f_{m}=\bar{Q}_{\mathrm{md}}, \\
\frac{d Q_{\mathrm{sd}}}{d t}=-v_{s} \cdot a_{2} \cdot f_{s}=\bar{Q}_{\mathrm{sd}} .
\end{gathered}
$$

As the taphole continuously erodes during the tapping, the effective taphole diameter $\left(D_{\text {th }}\right)$ at any point of time (accordingly, the cross-sectional area of taphole) is correlated with the taphole erosion coefficient $\left(K_{\mathrm{th}}=1.493 \times 10^{-6} \mathrm{~m} \mathrm{~s}^{-1}\right)$ [6] and the drill diameter $\left(D_{\text {th } 0}\right)$ :

$$
D_{\text {th }}=D_{\text {th } 0}+K_{\text {th }}\left(t-t_{h}\right) \text {. }
$$

These instantaneous drain rates in addition to the production rates give the rates of change of metal and slag volumes $\left(\bar{Q}_{m}, \bar{Q}_{s}\right)$ in the hearth as follows:

$$
\begin{gathered}
\frac{d Q_{m}}{d t}=\frac{d Q_{\mathrm{mp}}}{d t}+\frac{d Q_{\mathrm{md}}}{d t}=\bar{Q}_{m}, \\
\frac{d Q_{s}}{d t}=\frac{d Q_{\mathrm{sp}}}{d t}+\frac{d Q_{\mathrm{sd}}}{d t}=\bar{Q}_{s} .
\end{gathered}
$$

Having the initial liquid quantities and rate of change of liquid quantity in hearth, the remaining amounts of liquids $\left(Q_{m}, Q_{s}\right)$ at any point of time are calculated according to the following equations:

$$
\begin{aligned}
Q_{m} & =Q_{m 0}+\int_{t_{h}}^{t} \bar{Q}_{m} d t \\
Q_{s} & =Q_{s 0}+\int_{t_{s}}^{t} \bar{Q}_{s} d t
\end{aligned}
$$

Taking in to account the hearth geometry (diameter $D_{h}$ $=8.4 \mathrm{~m}$, accordingly, hearth area, $\left.a_{1}\right)$ and the coke grid void fraction $(\varepsilon=0.3)$, the liquid volume change rates are converted into liquid height change rates $\left(\bar{h}_{m}, \bar{h}_{s}\right)$, which are used to find respective liquid height $\left(h_{m}, h_{s}\right)$ at any point of time taking in to consideration the initial metal and slag heights $\left(h_{m 0}, h_{s 0}\right)$ as follows:

$$
\begin{gathered}
\frac{d h_{m}}{d t}=\frac{\bar{Q}_{m}}{\varepsilon \cdot a_{1}}=\bar{h}_{m}, \\
\frac{d h_{s}}{d t}=\frac{\bar{Q}_{s}}{\varepsilon \cdot a_{1}}=\bar{h}_{s}, \\
h_{m}=h_{m 0}+\int_{t_{h}}^{t} \bar{h}_{m} d t, \\
h_{s}=h_{s 0}+\int_{t_{h}}^{t} \bar{h}_{s} d t .
\end{gathered}
$$

On the basis of rate of change of height of liquid metal $\left(\bar{h}_{m}\right)$ and slag $\left(\bar{h}_{s}\right)$ using (6) and (7) and the predefined cutoff level, the slag-out time $\left(t_{s}\right)$ and the cast closing time $\left(t_{c}\right)$ are predicted. During the data collection for this work, it was found that the slag started coming out when there was still $150 \mathrm{~mm}$ of metal level in the hearth; hence, it is used as a cutoff level to predict the slag-out time $\left(t_{s}\right)$. A flowchart for drain rate and liquid level calculation is provided in Figure 2. All of the calculation steps in the model are sequential and interrelated. The startup of calculations for time $t$ draws the necessary values for variables from last step. These calculations are iterative in nature; thus, they are incorporated into a computer program.

The Bernoullis equation gives the fluid flow in the ideal case; so to derive the actual flow rates from the blast furnace hearth, $v_{m}$ and $v_{s}$ values need to be corrected in order to include the effect of friction, viscosity and pressure variations, and so forth. The friction depends on the quality of the mud gun clay used, the drilling practice, and the taphole length. In the same way, the viscosity depends on the liquid temperature and composition. Although the effect of furnace inner pressure has been taken into account, the load on the fluid surface, which is considered constant here, may vary in the long run. Now, many of the parameters, stated previously are not readily available in day-to-day operations; hence, the contributions of all of them are consolidated in terms of tunable parameters designated as "flow factors" $\left(f_{m}\right.$ and $\left.f_{s}\right)$ which are used to correct the fluid flow and calibrate the model in case of any deviation in the process parameters.

The model described above inherits the capability to re-calibrate and keep itself updated with the calculated parameters values. The differences in event times $\left(t_{s}, t_{c}\right)$ are calculated from the model predicted and the corresponding actual values. The flow factors $\left(f_{m}\right.$ and $\left.f_{s}\right)$ values are optimized to eliminate these differences. The optimized flow factors values are saved and based on a predefined data pool and their average values are derived. Now, depending on the difference between the present and the optimized values of 


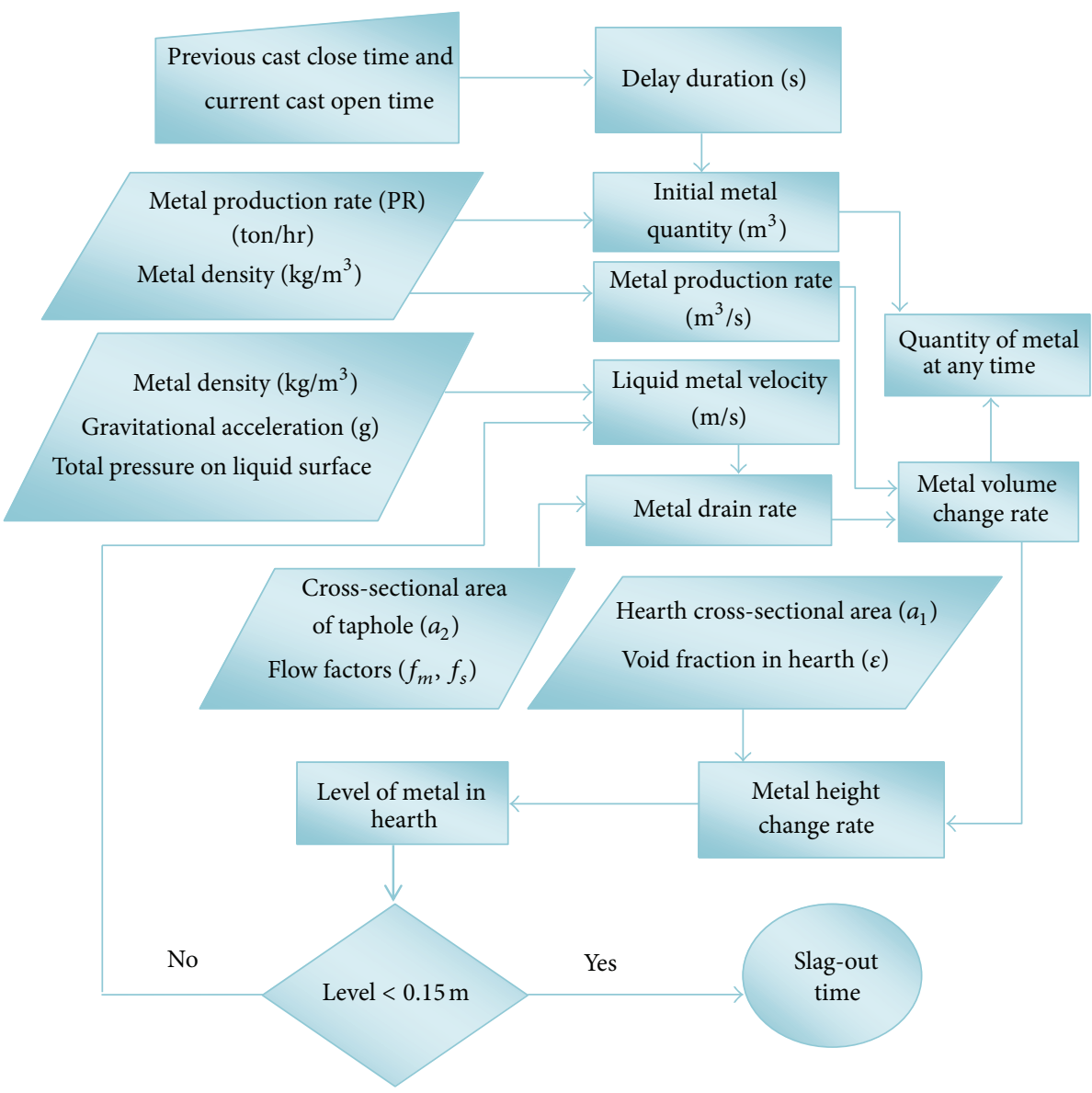

FIGURE 2: Flow-chart for drain rate and liquid level calculation to predict slag-out time from blast furnace hearth.

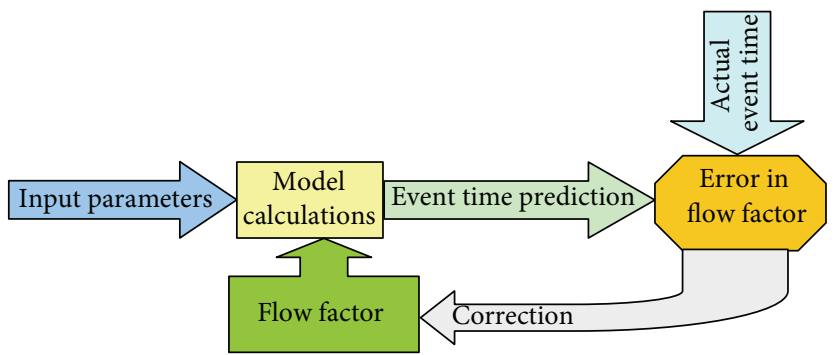

FIGURE 3: Flowchart for flow factor optimization.

flow factors, the correction factor is suggested as shown in Figure 3.

\section{Results and Discussion}

The results obtained by the model calculations are used for graphical representation of the liquid level variation in hearth as shown in Figure 4, which depicts the quantity of hot metal and slag present in the hearth at four distinct times. In the present study, it was observed that for the majority of cases the maximum liquid level in the hearth was $1.5 \mathrm{~m}$ above the taphole. Assuming the position of raceway bottom to be at about $1 \mathrm{~m}$ below tuyere center line, it still leaves a head space of $1.5 \mathrm{~m}$ between liquid level and tuyere. This modeled level matches well with the actual blast furnace practice, and, subsequently, smooth BF campaign is ensured as the blowing parameters never got disturbed due to raising liquid levels.

The volume flow rates and mass flow rates, when plotted individually for metal and slag against time duration as shown in Figures 5(a) and 5(b), reveal that there is a steep increase in volume flow rate for slag but equal steep decrease in slag mass flow rate after slag-out time $\left(t_{s}=64 \mathrm{~min}\right.$ after tap open). This phenomenon can be attributed to the lower density of liquid 


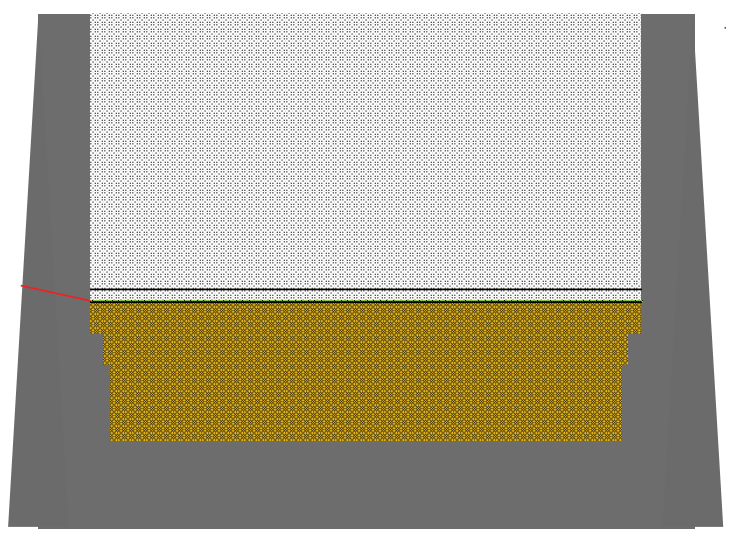

Previous tapping closed $(t=0 \mathrm{~min})$

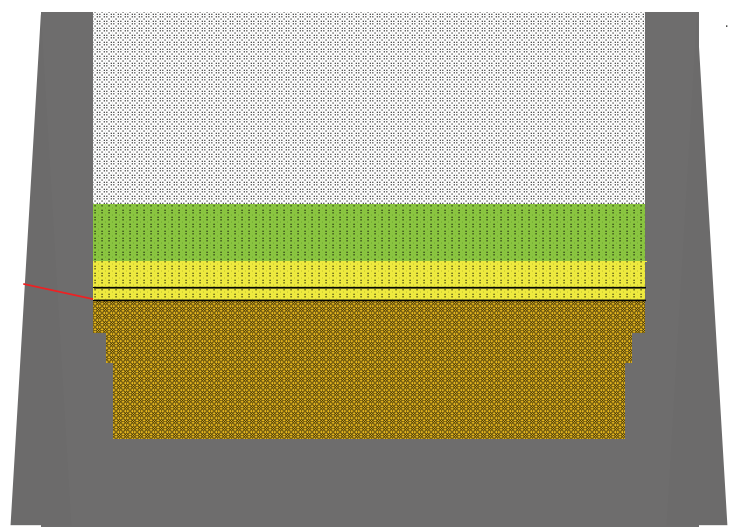

After $t_{h}$, before $t_{s}(t=35 \mathrm{~min})$

Liquid slag

Liquid metal

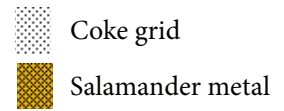

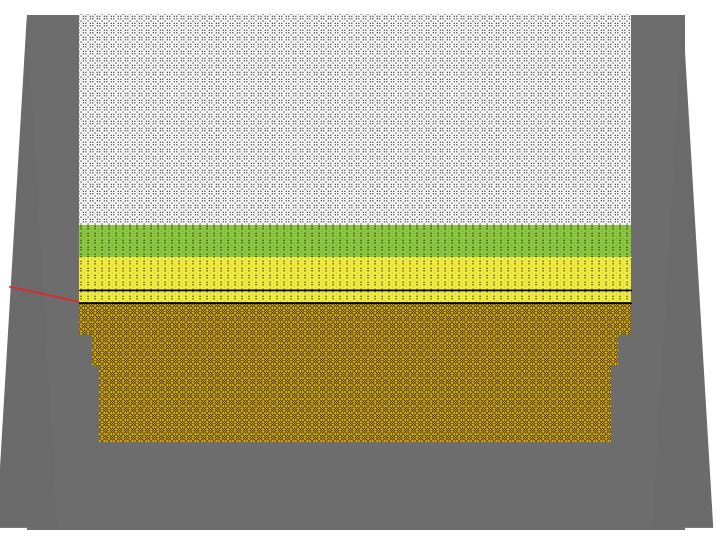

Tapping closed, during holding $t_{h}(t=20 \mathrm{~min})$

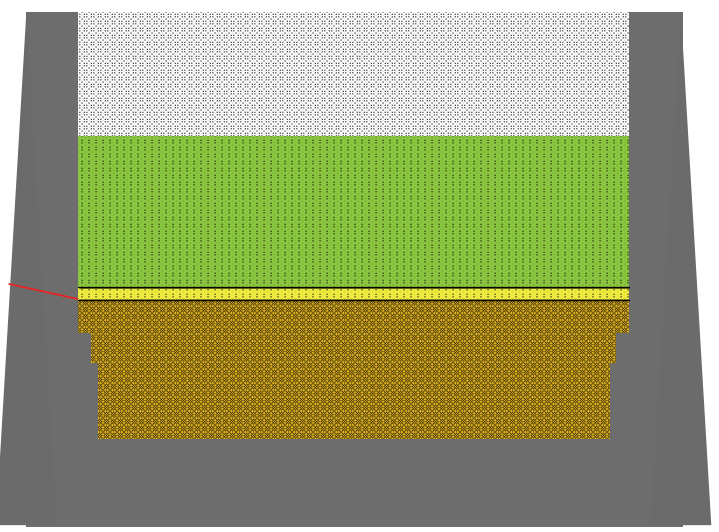

After $t_{s}$, before $t_{c}(t=70 \mathrm{~min})$

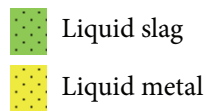

FIGURE 4: Model predicted liquid levels in the BF hearth at four distinct times.

slag than that of the metal. The same types of drainage trends are also observed in the plant under consideration. But for the combined plot for fluid flow, Figures 5(c) and 5(d) show an increase in both volumetric and mass flow rates during the slag flow part. It is due to the fact that whatever metal is produced it gets drained out with the slag which increases volume and mass of the tapped liquid. Calculated data plot for liquid metal and slag level variation in hearth against time, starting from the closing time of the last cast (i.e., including holding time $t_{h}$ ), is shown in Figure 6. It reveals that both liquid metal and slag level increase during the holding time $\left(t_{h}=20 \mathrm{~min}\right)$; after that, when taphole gets opened, the liquid metal only starts to come out from the hearth, and its level decreases, but the slag level continuously increases as no slag has drained until slag-out time $\left(t_{s}=84 \mathrm{~min}\right)$. During only the metal flow period, the volume of liquids drained remains less than the volume of liquids produced; hence, the total liquid level in hearth increases continuously with a reduced rate. At $t_{s}$, the total liquid level reaches at maximum due to accumulation of slag. After $t_{s}$, when slag starts coming out from the hearth, the total liquid level in hearth decreases, and, finally, at tapping close time $\left(t_{c}=138 \mathrm{~min}\right)$, there remains almost no liquid pool in hearth. By analyzing this trend, the casting practice can be tuned so that the total liquid level should not increase beyond the desired height at any point of time. It limits the buoyancy force exerted by the liquids and prevents the blast pressure from increasing due to excess liquid accumulation in hearth.

The model was tested on 227 castings of JSPL BF-II in October 2011, and it was found that the predicted slag-out time $\left(t_{s}\right)$ and the cast closing time $\left(t_{c}\right)$ are within a range of 10-15 minutes of the actual tapping data (Figure 7). The $t_{s}$ was matching in $95 \%$ cases, whereas $t_{c}$ was matching in $88 \%$ cases. The large deviations can be attributed to human interaction or some abnormality during the tapping. It is evident that, with further fine tuning, the present results and predictions can be utilized to optimize the blast furnace tapping operation for a stable casting behavior. 


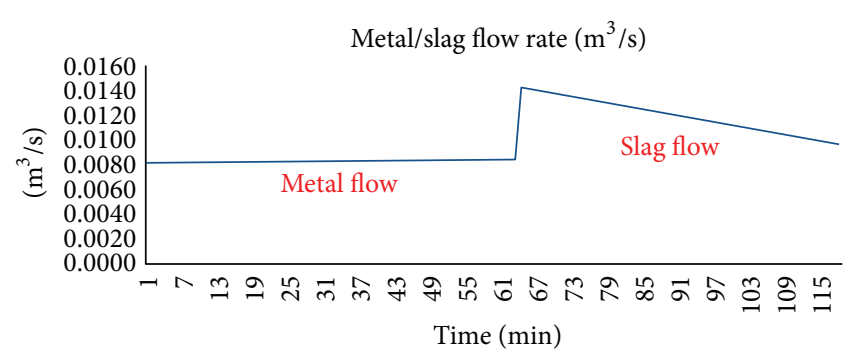

(a)

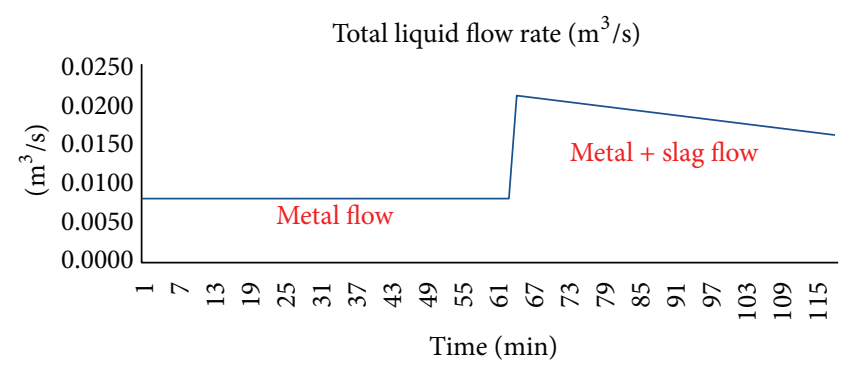

(c)

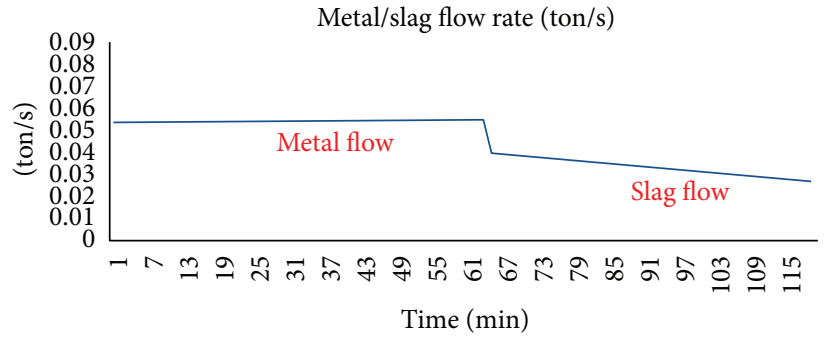

(b)

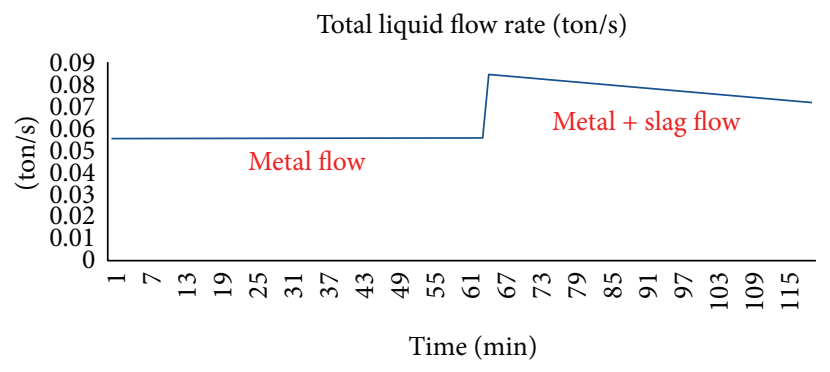

(d)

FIGURE 5: Metal and slag flow rates during tapping.

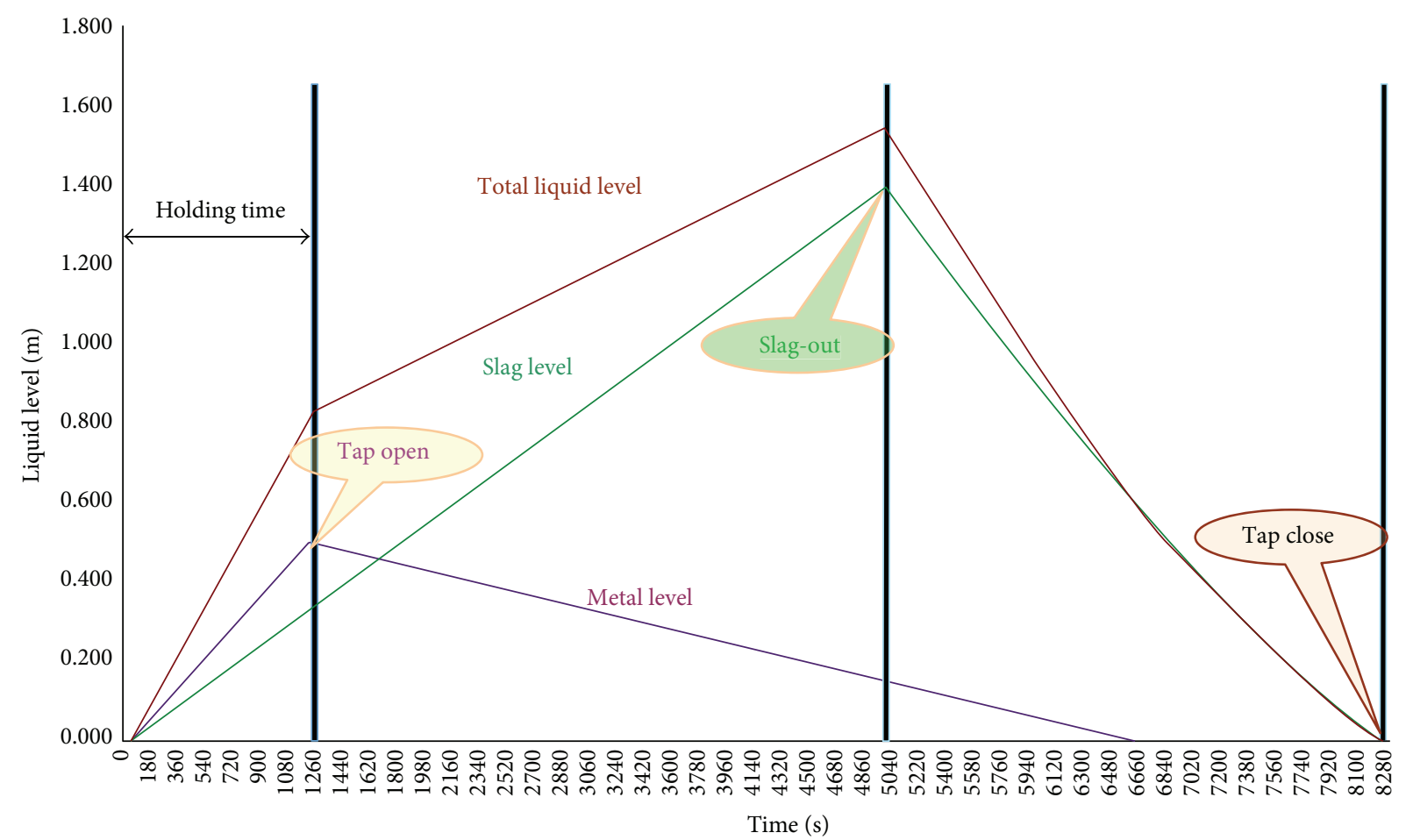

FIGURE 6: Variation in liquid levels in hearth during tapping.

\section{Conclusion}

A mathematical model on the drainage behavior has been developed which requires only the readily available data from an operating blast furnace. Effects of the unknown parameters, which vary from plant to plant, are taken into account by introducing flow factor concept and optimizing it. The developed model is very much useful as it provides the operator with a tool by which he/she can get a real-time view of the variation in the level of liquids in the hearth as well as the drainage behavior of the hearth. These data in turn help to control the parameters before they pose any threat to process stability. Our model predicts the slag-out time and the casting close time within acceptable range based on the 

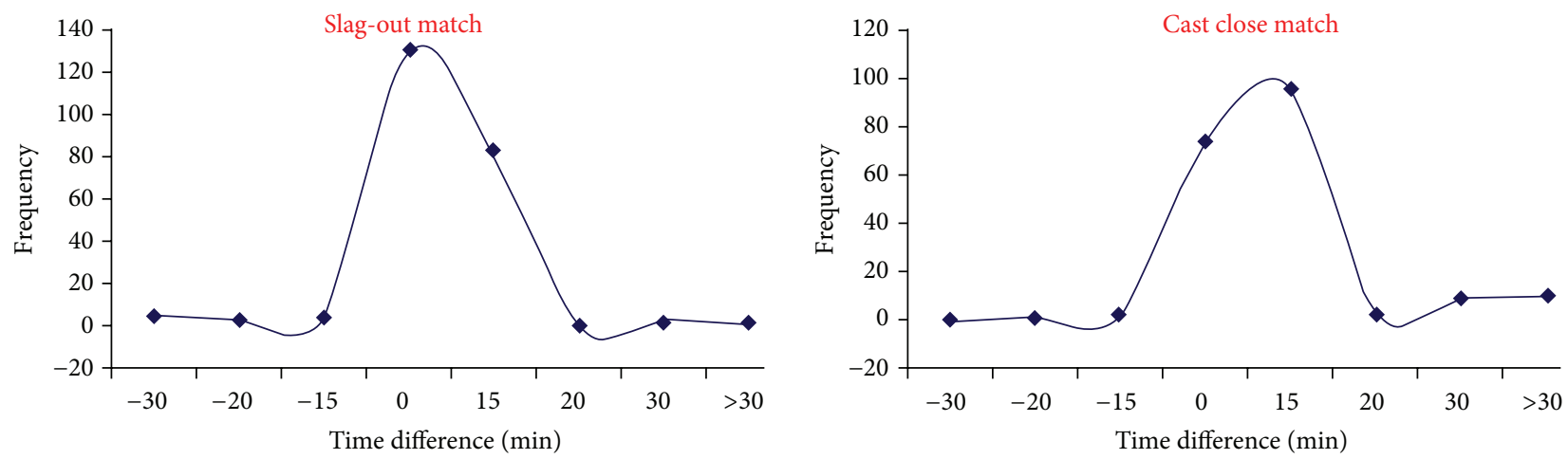

FIGURE 7: Comparison of the model predicted slag-out time and cast close time with the actual time.

trials conducted, and it can be used for process control and to judge irregularities in furnace operation.

\section{References}

[1] A. K. Biswas, Principles of Blast Furnace Ironmaking, SBA Publications, Kolkata, India, 1st edition, 2005.

[2] J. Brännbacka and H. Saxén, "Modeling the liquid levels in the blast furnace hearth," ISIJ International, vol. 41, no. 10, pp. 1131$1138,2001$.

[3] W. B. U. Tanzil, P. Zulli, J. M. Burgess, and W. V. Pinczewski, "Experimental model study of the physical mechanisms governing blast furnace hearth drainage," Transactions of the Iron and Steel Institute of Japan, vol. 24, no. 3, pp. 197-205, 1984.

[4] J. Brännbacka, J. Torrkulla, and H. Saxén, "Simple simulation model of blast furnace hearth," Ironmaking and Steelmaking, vol. 32, no. 6, pp. 479-486, 2005.

[5] T. Nouchi, M. Sato, K. Takeda, and T. Ariyama, "Effects of operation condition and casting strategy on drainage efficiency of the blast furnace hearth," ISIJ International, vol. 45, no. 10, pp. 1515-1520, 2005.

[6] K. Nishoka, T. Maeda, and M. Shimizu, "Effect of Various In-furnace conditions on blast furnace hearth drainage," ISIJ International, vol. 45, no. 10, pp. 1496-1505, 2005.

[7] W. M. Husslage, M. A. Reuter, R. H. Heerema, T. Bakker, and A. G. S. Steeghs, "Flow of molten slag and iron at $1500^{\circ} \mathrm{C}$ to $1600^{\circ} \mathrm{C}$ through packed coke beds," Metallurgical and Materials Transactions B, vol. 36, no. 6, pp. 765-776, 2005.

[8] W. B. U. Tanzil and W. V. Pinczewski, "Blast furnace hearth drainage: physical mechanisms," Chemical Engineering Science, vol. 42, no. 11, pp. 2557-2568, 1987.

[9] T. Nouchi, M. Yasui, and K. Takeda, "Effects of particle free space on hearth drainage efficiency," ISIJ International, vol. 43, no. 2, pp. 175-180, 2003. 

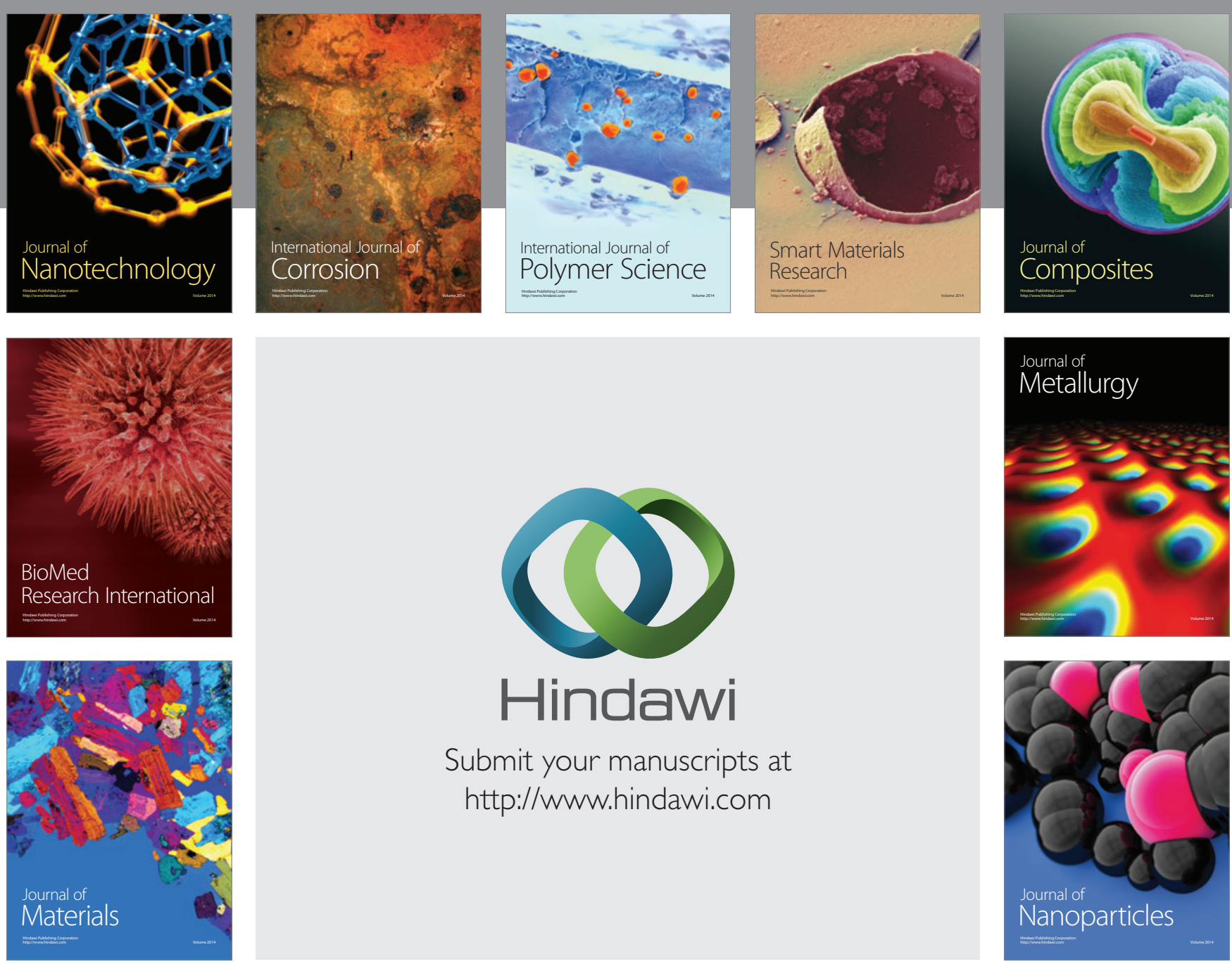

Submit your manuscripts at http://www.hindawi.com
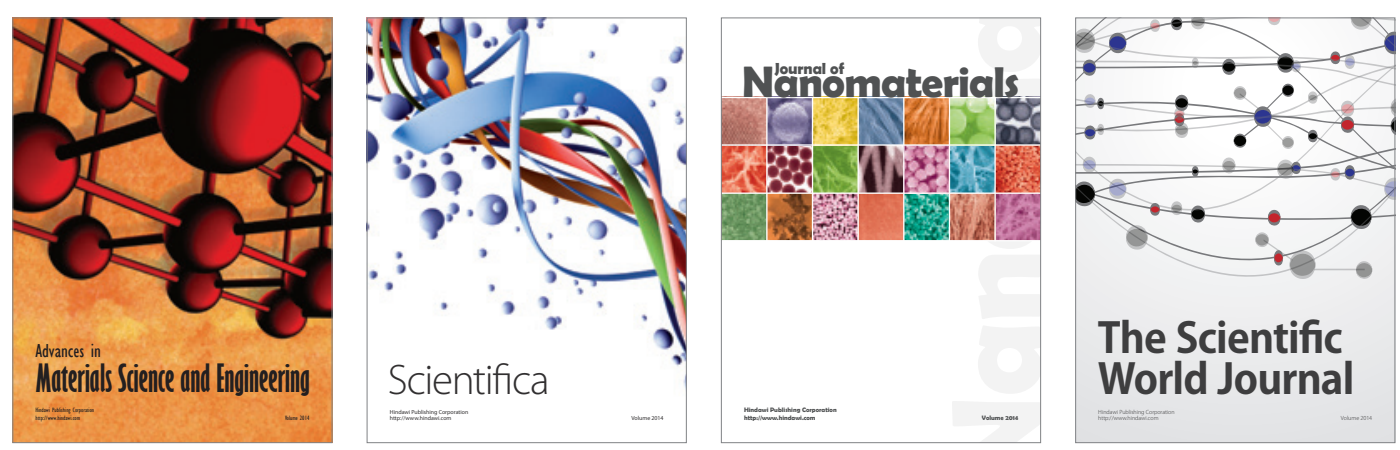

\section{The Scientific World Journal}
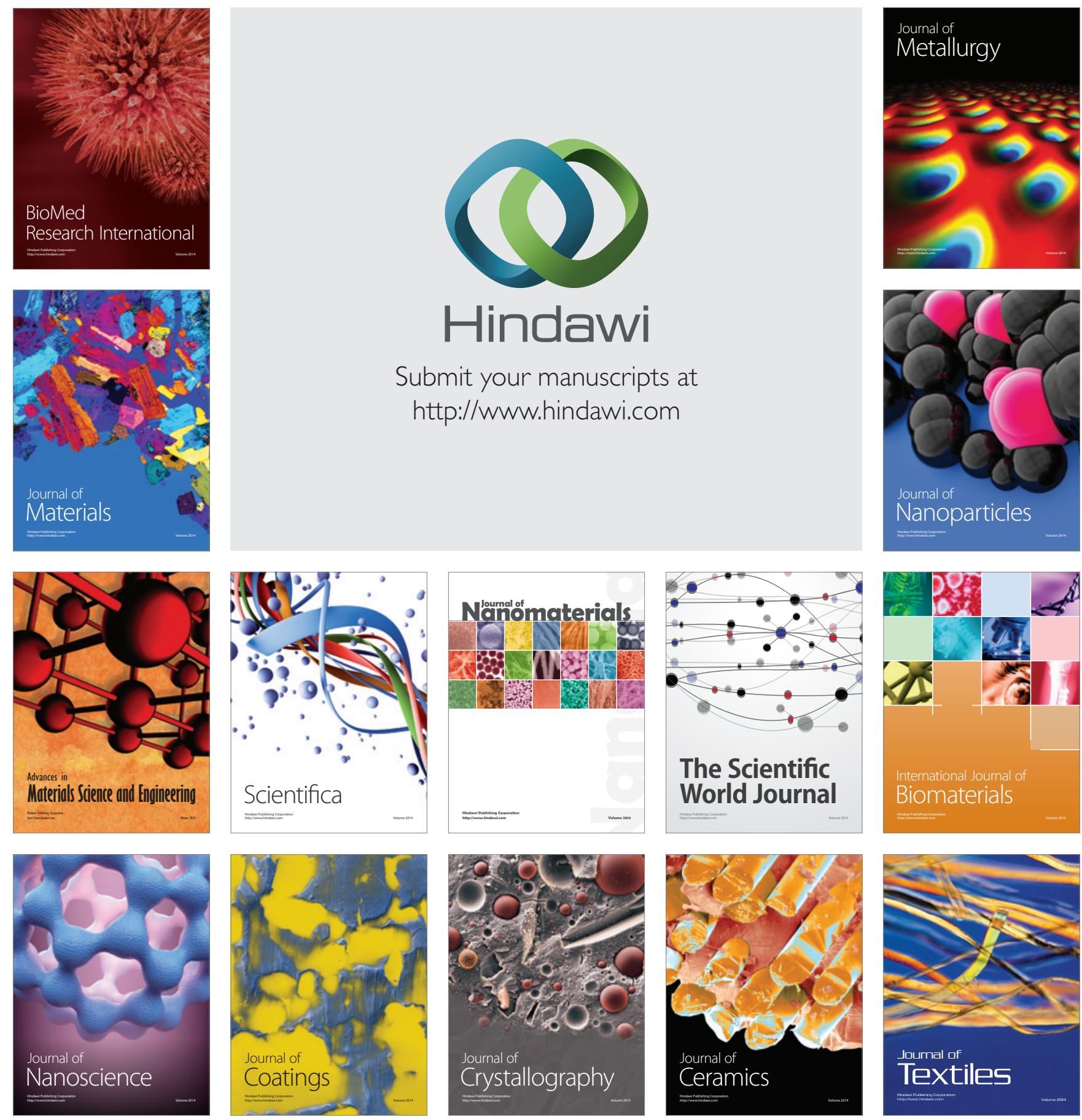